\title{
Desarrollo sostenible y ciudad
}

\section{Ramón Alberto Serna Isaza*}

Resumen. El concepto de desarrollo sostenible surge como alternativa ante el fracaso de las grandes concepciones económicas para promover el establecimiento de sociedades más igualitarias. En este documento se anali za el concepto de desarrollo sostenible y su relación con la crisis ambiental; se abordan los objetivos del mismo, según múltiples contextos. Se trata la relación entre ambiente, desarrollo y crecimiento, principalmente a través de la huella ecológica de las ciudades y el efecto que tiene sobre la sostenibilidad la localización de las actividades económicas, los patrones de urbanización y se discuten aspectos propios del desarrollo sostenible en las ciudades latinoamericanas. Palabras clave: desarrollo sostenible, ciudad, medio ambiente, desarrollo, ética, valoración ambiental, huella ecológica, urbanización latinoamericana.

* Biólogo. Especialista en Sistemas de Información Geográfica. Alumno del Programa de Estudios de Maestría en Geografía del Convenio UPTC-IGAC. Correo electrónico: raserna@hotmail.com 


\section{Introducción}

Los modelos actuales de desarrollo generan acumulación de riqueza, concentrando las fuentes de energía, las materias primas y con su afán materialista, incrementan el contraste entre los países desarrollados, ricos y la marginalidad y pobreza de los países y sociedades de la periferia. La globalización tiende a conducir a una homogeneización que conlleva a la pérdida de la cultura como valioso instrumento de adaptación al medio. De manera reiterada se ha planteado que la crisis ambiental que esto ha generado, se debe principalmente a las formas injustas de producción y distribución de riquezas, las cuales conllevan, entre otras, a la violencia como forma generalizada de respuesta en muchos países latinoamericanos.

La incapacidad de la teoría económica para hacer frente al agotamiento de recursos, a los costos ambientales externos y a los limitantes ecológicos; así como el hecho de que el crecimiento material exponencial indefinido no es sostenible, aunque si lo puede ser el crecimiento en conocimiento tecnológico, en educación o en salud, han conducido a diversos grupos a plantear nuevos paradigmas de desarrollo, no necesariamente basados en la acumulación de riquezas, sino en la sostenibilidad como valor de escogencia moral, aceptando la equidad social e intergeneracional como éticas supeditadas.

En el presente documento se trata la evolución del concepto de desarrollo soste- nible, su relación con la crisis ambiental, los objetivos que persigue, la sostenibilidad como valor, la relación existente entre ambiente, desarrollo y crecimiento y como este es abordado en las ciudades latinoamericanas. El documento parte del planteamiento que para lograr los objetivos del desarrollo sostenible, deben revisarse los actuales modelos de desarrollo.

\section{Evolución del concepto de desarrollo sostenible}

La idea de desarrollo, la cual se centra en un permanente proceso acumulativo de cambio y transformación de la estructura económica y social, como toda corriente de pensamiento implica una visión del deber ser, elemento prospectivo e ideología que conducirá a unas conclusiones por el método de análisis que se utilice (Sunkel y Paz, 1991).

Por esta razón, el concepto de desarrollo ha sido abordado según múltiples perspectivas; entre ellas el crecimiento, que define el desarrollo según el ingreso por habitante y el proceso de desarrollo por la tasa de crecimiento (Sunkel y Paz, 1991). De la misma manera, el desarrollo económico fue definido en la década de 1960 por Okun y Richardson como un 'mejoramiento sostenido, secular en bienestar material, que podemos considerar reflejado en un creciente flujo de bienes y servicios' (Carrizosa, 1998).

Por el contrario, otras corrientes consideran el subdesarrollo como sucesión de

138 Ramón Alberto Serna I. 
etapas que van desde las primitivas o tradicionales hasta las más desarrolladas o modernas, y las sociedades subdesarrolladas serán el camino hacia la moderna sociedad industrial, la cual es concebida implícita o explícitamente como modelo (Sunkel y Paz, 1991). El subdesarrollo no puede ser concebido como condición inherente a los países pobres, sino como consecuencia de procesos mundiales de acumulación y reproducción del capital, motivado por la expoliación de recursos de América Latina a Europa a partir del siglo XVI (Fundagro, 1996).

El desarrollo como proceso de cambio estructural global se centra sobre reformas estructurales que son promovidas, orientadas y planificadas por el Estado, y están acompañadas por financiación externa y comercio internacional. Esta posición metodológica implica que el desarrollo es algo que parte de la sociedad desea y por lo tanto es necesario identificar a qué agentes interesa y para qué, a quiénes perjudica y por qué, para que los actores sociales que persiguen las metas del desarrollo, puedan precisar las estrategias de acción, las cuales deben perseguir como finalidad última la igualación de oportunidades sociales, políticas y económicas, tanto en el plano nacional como en relación con sociedades con niveles de vida más elevados (Sunkel y Paz, 1991).

De esta forma, el panorama latinoamericano ha estado dominado por dos grandes concepciones económicas: el desarrollismo y el monetarismo neoliberal que comparten el no haber logrado lo que originalmente se propusieron (Cepaur, 1986).

El desarrollismo generó ideas y corrientes de pensamiento y es durante este periodo que aparecen entidades como la CEPAL, el BID, la ALAC, el Pacto Andino y otras importantes iniciativas regionales tales como la Alianza para el Progreso. A nivel nacional aparecen las instituciones de planificación, las corporaciones de fomento de la producción, las políticas que impulsan la industrialización y revierten la composición demográfica priorizando el desarrollo urbano, las reformas bancarias, el mejoramiento de los sistemas estadísticos, la promoción popular y los variados intentos de reformas estructurales, así como la defensa de las exportaciones (Cepaur, 1986).

El fracaso de estas iniciativas se ha debido principalmente a su incapacidad para controlar los desequilibrios monetarios y financieros, a la concentración que generó la estructura productiva - especialmente la industria- y a que su enfoque economicista, descuidó otros procesos sociales y políticos que comenzaban a emerger con fuerza, especialmente después del triunfo de la Revolución Cubana (Cepaur, 1986).

En estas corrientes desarrollistas pueden enmarcarse planes de desarrollo formulados por diversos gobiernos colombianos. El Plan de las Cuatro Estrategias (19701974), consideró al sector de la construcción como el que podría reactivar la economía debido a su efecto multiplicador y que presentaba características muy par- 
ticulares en cuanto a la demanda de factores: por una lado utiliza mano de obra no calificada, con bajos requerimientos de capital y el componente importado era relativamente bajo (Vallejo Zamudio, s.f.).

Esta orientación se ajustó a las ideas expuestas por Lauchin Currie, esbozadas inicialmente por el autor en el programa conocido como Operación Colombia y, cuya idea central sobre el desarrollo, es el estímulo a la demanda real. Considera que 'la demanda es reducida porque hay una gran masa de desempleados que no participa del proceso productivo, o de subempleados cuyo ingreso, es muy bajo; esto, necesariamente, contrae de manera significativa la demanda'(Vallejo, 1991 citado por Vallejo Zamudio, s.f.).

Posteriormente irrumpe el monetarismo neoliberal con toda su fuerza. 'Si el desarrollismo fue generador de ideas, el monetarismo ha sido fabricante de recetas' (Cepaur, 1986). Su fracaso se debe a tres razones (Cepaur, 1986): Primero, a pesar de impulsar el crecimiento económico, no genera desarrollo en sentido amplio. Segundo, porque sus supuestos de racionalidad económica son profundamente mecanicistas y por 10 tanto inadaptables a las condiciones de países pobres, donde la miseria no se erradica como consecuencia de la liberalización de un mercado del que los pobres se encuentran, de hecho, marginados. Tercero, porque en mercados restringidos $y$ oligopólicos, con grupos de poder económico que no enfrentan fuerzas capaces de limitar su comportamiento, la actividad económica se orienta con sentido especulativo, generando concentración socialmente inaceptable.

Ninguna de estas orientaciones ha promovido el establecimiento de sociedades más igualitarias. Por ello, se duda de la validez ética de los objetivos económicos del desarrollo y la falsa relación felicidadconsumo: 'La ventaja del crecimiento económico no es que la riqueza incremente la felicidad, sino que incrementa el rango de posibilidades humanas para la escogencia. Es muy difícil correlacionar riqueza y felicidad. La felicidad resulta de la manera como uno ve la vida, tomándola como viene, buscando lo placentero más que no lo sea, y viviendo sin miedo de lo que el futuro pueda traer. La riqueza podría incrementar la felicidad, si el incremento de los recursos es mayor que el de los deseos, lo cual no es necesariamente de esta forma, y no hay evidencia que el rico sea más feliz que el pobre, o que las personas sean más felices en tanto sus ingresos aumentan. La riqueza merma la felicidad si al uno adquirirla, deja de aceptar la vida como viene, y se afana mucho más por los recursos y el futuro. Ciertamente existe alguna evidencia de ser este el caso, en la medida en que el crecimiento económico resulta de estar alerta, de buscar y aprovechar las oportunidades económicas, es de esperar que ello se asocie con menor felicidad que la que encontramos en sociedades en donde la gente no se ocupa tanto del crecimiento' (Lewis, 1955).

Dentro de esta línea política puede enmarcarse el Plan para Cerrar la Brecha (1974-1978). Se cuestiona la inter-

140 Ramón Alberto Serna I. 
vención del Estado y se propone al mercado como el mejor asignador de recursos mediante el mecanismo de los precios (Vallejo, 1989 citado por Vallejo, s.f.). Se sugería que la apertura debería hacerse en forma gradual y selectiva, según las condiciones concretas de la economía, para que la liberación del comercio exterior no creara traumatismos en el sector productivo. Aunque la industrialización mediante la sustitución de importaciones no ha tenido buenos resultados, se propuso un desmonte gradual a las restricciones principales a las importaciones y una devaluación del tipo de cambio para evitar mayores traumatismos (Vallejo, s.f.).

Estas tendencias continuaron con el Plan de Integración Nacional que se sustentó en la mejor asignación de recursos vía la libertad económica y se otorgó al Estado un papel prioritario en el manejo del gasto público (Vallejo, s.f.).

En una línea desarrollista, pero con algunos elementos propios de la sostenibilidad (aunque no fueron implementados como tales), puede mencionarse el Plan de Desarrollo con Equidad (1982-1986), que aunque también promovió las políticas de sustitución de importaciones, tuvo una mayor visión a corto y largo plazo, implementando de manera sustancial la importancia de la equidad como factor de desarrollo. La equidad también constituye un factor manifiesto de desarrollo en el Plan de Desarrollo de Economía Social (1986-1990), al igual que el crecimiento que sería promovido por las exportaciones (Vallejo, s.f.).
Por el contrario, el Plan de la Revolución Pacífica (1990-1994), fue muy crítico frente a la sustitución de importaciones y a la intervención del Estado y, basado en el principio que el mercado es el mejor asignador de los recursos plantea que éste debe actuar principalmente en aspectos de tipo social y no debe participar en la actividad productiva. Ocurre un cambio de énfasis, el cual recae sobre la oferta, a diferencia de otros planes cuyo centro recaía en la demanda (Vallejo, s.f.).

La participación ciudadana retomó protagonismo dentro del Plan de El Salto Social (1995-1998) (Restrepo, 1995), aunque muchas de sus iniciativas quedaron plasmadas únicamente como iniciativas (como ha sucedido con los otros planes de desarrollo). Se propone, a diferencia del plan anterior, que el sector público debe ser instrumento de desarrollo (Sarmiento Palacio, 1995). Esta misma orientación, basada en un mayor acercamiento entre el gobierno y el ciudadano, es clara dentro de la promoción de los procesos de descentralización en el Plan de Desarrollo del Cambio para Construir la Paz (1998-2002) y que propone el ordenamiento territorial como objetivo central de esta estrategia (Departamento Nacional de Planeación, 1998).

El concepto de sostenibilidad es antiguo en las ciencias económicas y es completamente opuesto al pensamiento ambiental: el crecimiento sin límites (Carrizosa, 2000). Desde la antigüedad existe controversia entre las visiones dinámicas del mundo y las interpretaciones estáticas del universo. La idea de progreso es fortale- 
cida con el iluminismo del siglo XVIII y constituye la raíz filosófica de los desarrollismos, incluido el actual neoliberalismo. En los análisis de la economía neoclásica se emplean conceptos como externalidades positivas y negativas, pero no se consideran los efectos sinergéticos de los cambios acumulables. En los actuales análisis se asume una gran incertidumbre en el comportamiento de los sistemas complejos, pero al mismo tiempo se reconoce la necesidad de establecer patrones de cambio inducido y señalar causas para su operacionalidad (Carrizosa, 2000).

Los clásicos tenían dudas sobre la posibilidad teórica de la sustentabilidad y plantearon que el cubrimiento de la totalidad de las necesidades y el empleo total de los factores conduciría al estancamiento y no al crecimiento continuo. Por su parte, Shumpeter y Marx consideraron que era posible el progreso sin límites y por lo tanto la sostenibilidad, la cual estaría liderada por los trabajadores o por los empresarios según las respectivas visiones. De otra parte, el pensamiento malthusiano constituye uno de los fundamentos de las líneas ambientalistas que duda de la capacidad tecnológica para lograr equilibrar la demanda ascendente creada por el crecimiento geométrico de la población (Carrizosa, 2000). Mientras que en la cultura occidental no ha sido muy común el reconocimiento de límites, en Oriente siempre se ha admitido su existencia (de tipo económico, biofísico, humano, social, etc.) (Carrisoza, 2000), a partir de lo cual se generan múltiples modelos de desarrollo sostenible, ya que son diversas las formas de ver el mundo.
La visión ecosistémica es clara a través de los enfoques planteados por la Escuela de Ecología Humana de Chicago y la física social de Stewart y Zipf, dentro de la geografía humana cuantitativa. Estas visiones constituyeron pilares para la conceptualización positiva de la ciencia social, cuyas ideas centrales, ampliamente relacionadas con el ambiente, para el caso de la obra de Chicago son las siguientes (Mellor, 1977 citado en Unwin, 1995):

1. Las ciudades pueden contemplarse como comunidades ecológicas.

2. El valor de la tierra es reflejo del orden natural.

3. Las ciudades están sujetas a un ciclo de invasión y sucesión en el espacio.

4. Las áreas naturales reflejan la base espacial fundamental de toda organización social.

5. La distinción entre los órdenes natural y moral de las ciudades proporciona una organización estructurada de modelos de estilos de vida.

A partir del debate sostenido en la Primera Conferencia Internacional sobre Desarrollo Humano celebrada en Estocolmo (1972), se planteó que la superación de la pobreza permitiría resolver conflictos de desigualdad social y de deterioro de los ecosistemas en el Tercer Mundo (Fundagro, 1996). En respuesta a estos debates surgieron diferentes corrientes teóricas, entre ellas el

142 Ramón Alberto Serna I. 
ecodesarrollo que proponía un desarrollo basado en las características ecológicas de cada región, fomentando tecnologías alternativas, así como la valoración de las experiencias locales y una amplia participación de los pueblos (Ángel, 1994 citado por Fundagro, 1996).

Por otra parte, el Desarrollo a Escala Humana se concentra y sustenta en la satisfacción de las necesidades humanas fundamentales, en los niveles crecientes de autodependencia y en la articulación orgánica de los seres humanos con la naturaleza y la tecnología, de los procesos globales con los comportamientos locales, de lo personal con lo social, de la planificación con la autonomía y de la Sociedad Civil con el Estado (Cepaur, 1986). De esta manera, debe existir conjugación entre las sinergias con la eficiencia, centrando la atención sobre los procesos más que sobre los resultados y asume una posición muy crítica sobre el crecimiento económico debido a que éste ha conducido a una mayor concentración del bienestar, a inequidades más marcadas y la generalización de la pobreza y muchos otros problemas (Max-Neef, 1998).

Necesidades humanas, autodependencia y articulaciones orgánicas, son los pilares fundamentales que sustentan el Desarrollo a Escala Humana (Cepaur, 1986). Estos se construyen a partir del protagonismo real de las personas como resultado de privilegiar tanto la diversidad como la autonomía de espacios en los que el protagonismo sea realmente posible.
Lograr la transformación de la personaobjeto en persona-sujeto del desarrollo es, entre otras cosas, un problema de escala porque no hay protagonismo posible en sistemas organizados jerárquicamente desde arriba hacia abajo, por lo cual se requieren modificaciones en la democracia, tendientes a una práctica más directa y participativa que contribuya a revertir el rol tradicionalmente semipaternalista del Estado Latinoamericano y estimule soluciones creativas, congruentes con las aspiraciones reales de las personas (Cepaur, 1986).

Las principales corrientes dentro del desarrollo sustentable son la del neoliberalismo sustentable que coincide con el concepto de sustentabilidad débil, fundamentado en la posibilidad de sustitución completa del capital natural por otros tipos de capital; la corriente del desarrollo sin crecimiento, es decir en el cual hay expansión o realización de potencialidades, pero no adición de materiales (crecimiento), liderada por Germán Daly y la escuela del desarrollo sostenible multifactorial liderada por el Banco Mundial que enfatiza en la estabilidad de los sistemas biológicos y físicos (Carrizosa, 2000). Algunos neoliberales plantean que una sociedad sostenible será aquella en donde el mercado sea completamente libre y abierto, pero existen distorsiones del mercado relacionadas con derechos de propiedad mal definidos o inexistentes, recursos naturales no valorados e incertidumbre (Carrizosa, 2000). 
Según el énfasis, las aproximaciones al desarrollo sostenible se han agrupado en tres enfoques: económico, ecológico y sociológico (Fundagro, 1996): el enfoque económico propone la optimización de los flujos de ingresos y el uso eficiente de los recursos; el ecológico hace énfasis en la estabilidad ecosistémica y considera que el desarrollo debe permitir preservar la diversidad biológica y genética; los enfoques sociológicos buscan mantener la estabilidad de los sistemas sociales y culturales, dentro de un marco de equidad, por lo cual asume que las demandas sobre el medio ambiente están culturalmente determinadas.

\section{La crisis ambiental}

La comisión Brundtland (World Commission on Environment and Development, 1987) plantea la necesidad de cambiar la cualidad del desarrollo hacia el cumplimiento de las necesidades básicas de trabajo, energía, agua y saneamiento de la sociedad, para asegurar niveles sostenibles de población, al tiempo que se conserva y mejora la base de los recursos naturales mediante la reorientación de la tecnología y el mayor manejo de los riesgos y la fusión de la economía y el ambiente en los procesos de tomas de decisión social, avances que conducirían al 'Desarrollo Sostenible'. El logro de estos objetivos requiere el diseño de un sistema económico y social que asegure que estas metas sean sostenidas, es decir, que el ingreso real aumente, que los estándares de educación aumenten, que la salud de la nación aumente, que mejore en general la calidad de vida de la población.

El agotamiento de los recursos naturales y la degradación ambiental pueden convertirse en restricciones definitivas al desarrollo socio-económico (Torres Toro, 1998). Algunos de los problemas generados por la crisis ambiental son los niveles de consumo de agua como limitante estructural del desarrollo actual; la desnutrición en países periféricos que continúa en aumento, a pesar de cálculos que indican que hay suficiente producción para la población mundial; la marginalización tanto de la ciudad como del campo; la sobrepoblación en el tercer mundo; el modelo político, con todos sus vicios que parece no ser viable en muchos países; la homogeneización cultural que disminuye la capacidad de respuesta a las amenazas ambientales, ocasionando en muchas ocasiones que las poblaciones se comporten de manera pasiva y pierdan capacidad de respuesta frente a los problemas ambientales, situación condicionada en gran medida por los medios masivos de comunicación.

La situación ambiental actual, abordada a través de diferentes disciplinas como la economía, la ecología, la teoría social y los estudios de desarrollo, permiten conceptualizar una serie de tópicos que han conducido a la mencionada crisis; entre ellos se pueden citar (Dovers 1989): costo externo de la producción, escasez de los recursos potenciales, límites físicos del crecimiento material indefinido, disminución del retorno social del creci-

144 Ramón Alberto Serna I. 
miento, inequidad global y disminución de la diversidad biológica. Aspectos que marcan la preocupación actual sobre la sostenibilidad global, entre ellos:

1. Los recursos están siendo utilizados o degradados a tasas que pueden comprometer significativamente a las generaciones futuras (p.e. combustibles fósiles, maderas, suelos).

2. Las basuras se acumulan a una tasa que también compromete el uso futuro de la biósfera (v.g. contaminación oceánica, eutroficación de cursos de agua, efecto invernadero)

3. La diversidad biológica está disminuyendo drásticamente, amenazando una gran proporción de vida no humana y el uso futuro de la biósfera por los hombres (p.e. bosques tropicales, diversidad genética de los cultivos).

4. Los modelos actuales de crecimiento y desarrollo crean muchos bienes, servicios y situaciones que no son necesariamente social o humanamente deseables (p.e. estrés, drogas, sobreconsumo).

5. Los actuales modelos de desarrollo son fundamentalmente inequitativos.

En reuniones recientes como la Cumbre de Río de Janeiro (1992), es claro el contraste de intereses que ha generado la crisis ambiental. Los países desarrollados plantean la necesidad de limitar las aspiraciones de crecimiento económico de los países pobres como medida de pruden- cia ambiental, sin ceder a sus propios niveles de consumo. Los países pobres, por su parte, defienden el derecho de alcanzar niveles de consumo elevados y logran que este derecho quede plasmado en la Carta de la Tierra, la cual fue firmada en Río por algunos jefes de Estado.

\section{Objetivos del desarrollo sostenible}

Como atributos de un futuro sostenible se plantean los siguientes aspectos (Dovers, 1989):

1. Continuación de la especie humana sobre la tierra.

2. Mantenimiento de los procesos ecológicos básicos.

3. Mantenimiento de la diversidad biológica.

4. Poblaciones humanas estables o reducidas.

5. Provisión de las necesidades básicas para todos los seres humanos.

6. Satisfacción de las necesidades no materiales para todos los seres humanos.

7. Reducción significativa en las tasas de uso de los recursos no renovables.

8. Tasas de producción de basuras no reutilizables o intratables significativamente bajas. 
9. Incremento de las tasas de uso de los recursos renovables de forma estable/ sostenible.

10. Concentración en la calidad/información/durabilidad de los bienes y servicios en lugar de un contenido basado en la masa/recurso.

11. Redistribución global de los medios de producción.

12. Reducción en el consumo material per cápita en el mundo desarrollado.

13. Incremento en el consumo material per cápita en el mundo 'en desarrollo'.

14. Devolución del poder/incremento de la autoconfianza dentro de escalas organizacionales pequeñas.

15. Satisfacción de las necesidades humanas de forma que ocasionen un uso de recursos y una producción de desechos mínimos.

Plantea la Comisión Brundtland (World Commission on Environment and Development, 1987) que el propósito del desarrollo sostenible requiere de:

- Un sistema político que asegure la participación ciudadana en el proceso de decisión.

- Un sistema económico, capaz de generar excedentes y tecnología en forma segura y sostenida.

- Un sistema social que provea soluciones para las tensiones generadas por el desarrollo desigual, como la creación de oportunidades adecuadas de generación de ingresos y mejores condiciones de vida para todos los estratos sociales, así como mejorar la gobernabilidad a través de la descentralización en la toma de decisiones e implementar autoridades locales democráticas (Centro de las Naciones Unidas para los Asentamientos Humanos, 1996).

- Un sistema productivo que respete la base ecológica.

- Un sistema tecnológico que busque nuevas soluciones.

- Un sistema internacional que promueva patrones sostenidos de comercio y financiación.

- Un sistema administrativo flexible y capaz de autocorrección.

Esto implica un cambio paradigmático en los modelos de producción, basado en el principio que el manejo adecuado del medio depende de una sociedad construida sobre la equidad y en la cual la cotidianidad local aporta valiosos elementos adaptativos que no han sido debidamente valorados en los procesos de planificación (esta gran capacidad para promover el desarrollo sostenible es abordada como 'Capital Social' dentro de la utilitarista jerga de la economía). Debe reconocerse que la ciencia y la tecnología no son las únicas formas válidas de construcción de conocimiento y de abordar la realidad; al igual que las ciudades deben permitir el desarrollo humano integral.

146 Ramón Alberto Serna I. 


\section{La sostenibilidad como valor}

Las definiciones de desarrollo sostenible tienen en común los conceptos de ambiente, futuro e igualdad, integrados por el hecho que las generaciones futuras deberían ser compensadas por las reducciones en el legado de recursos producidas por las acciones de las presentes generaciones. Es por lo tanto una política que deja más riqueza para el desarrollo futuro (Universidad Javeriana, s.f.). De esta manera implica un valor, ya que incorpora ideales personales, aspiraciones, conceptos y en general fija objetivos sociales. Esto ha conducido a plantear que las definiciones son muy laxas para ser aplicables a aspectos prácticos. Por ello, dentro de diferentes contextos, es importante reconocer el lugar correcto para dicha ética.

Una pregunta que continúa vigente en relación con la protección ambiental y el manejo de los recursos, es la forma como deben valorarse las clases de activos ambientales usados en la producción y el consumo, de tal forma que dicha reevaluación contribuya a una mayor equidad intergeneracional e intrageneracional (Centro de las Naciones Unidas para los Asentamientos Humanos, 1996). El mencionado informe discrimina los activos ambientales en cuatro formas (tabla 1):

Tabla 1

\section{Diferentes formas de activos ambientales}

\begin{tabular}{|l|l|}
\hline Activos no renovables & Activos renovables \\
RECURSOS & RECURSOS \\
- Combustibles fósiles & - Suelos \\
- Otros minerales & - Bosques \\
- Biodiversidad & $\begin{array}{l}\text { - Agua dulce } \\
\text { - Recursos marinos }\end{array}$ \\
\hline $\begin{array}{l}\text { Sumideros } \\
\text { - Desechos no biodegradables } \\
\text { (plásticos, químicos persistentes, } \\
\text { desechos nucleares de larga vida, } \\
\text { CFC, muchos gases de efecto } \\
\text { invernadero) }\end{array}$ & $\begin{array}{l}\text { Sumideros } \\
\end{array}$ \\
\hline
\end{tabular}

Fuente: Centro de las Naciones Unidas para los Asentamientos Humanos, 1996. 
Se ha trabajado fundamentalmente en la limitación del uso de los sumideros locales para desechos por parte de las industrias, con el fin de evitar su disposición sin tratar en ríos, lagos u otros cuerpos de agua o los altos niveles de contaminación en el aire, $\mathrm{o}$ en la racionalización en el uso de los recursos renovables, con el fin de promover patrones de uso con menos desperdicio; lo cual entra en contradicción con los paradigmas que preconizan valores basados en el consumo. En Colombia, estos aspectos son abordados a nivel normativo por la Ley 99 de 1993 que reglamenta las funciones de las corporaciones autónomas regionales (Título VI, artículos 23-41), las cuales emiten resoluciones que afectarán la gestión medioambiental municipal; p.e. la Corporación Autónoma Regional de Cundinamarca (CAR) emitió las Determinantes Ambientales para los Planes de Ordenamiento Territorial Municipal (Resolución CAR No. 1080 de 1998). La implementación de la normatividad vigente puede hacerse efectiva una vez los diferentes municipios aprueben sus respectivos Planes de Ordenamiento Territorial Municipal (reglamentados por la Ley 388 del 18 de julio de 1997). Desafortunadamente, existe una gran brecha entre la normatividad vigente y el cumplimiento de las disposiciones.

Sin embargo, es menor el progreso que se ha logrado en relación con el uso de los recursos no renovables y sumideros para desechos no biodegradables, como sucede con el 'sumidero global' para gases de efecto invernadero.
Es prioritario intervenir sobre las decisiones que implican costos sociales y ambientales, tanto en la vecindad inmediata, como en ecosistemas lejanos o para las generaciones futuras. Objetivo difícil de lograr debido al conocimiento incompleto acerca de la escala y naturaleza de los costos ambientales que los actuales patrones de producción y consumo están transmitiendo a las actuales y futuras generaciones. Muchos gobiernos y agencias de asistencia al desarrollo están implementando la evaluación del impacto ambiental como instrumento para identificar y predecir consecuencias ambientales de proyectos de desarrollo, con lo cual se busca anticipar consecuencias y mitigar o evitar el impacto (Centro de las Naciones Unidas para los Asentamientos Humanos, 1996).

La primera etapa de la evaluación consiste en identificar todos los posibles impactos ambientales del proyecto y las comunidades que afectaría. En la segunda fase se estima la gravedad de dichos impactos para los posibles planes que abordarían los objetivos del proyecto. Por último deben proponerse alternativas para minimizar los impactos ambientales negativos (Centro de las Naciones Unidas para los Asentamientos Humanos, 1996).

En Colombia, la Contraloría General de la Nación está involucrada en el desarrollo de metodologías que permitan evaluar el uso de los recursos a través de un sistema de 'Cuentas Ambientales' (Contraloría General de la República, 1994). Parte del problema surge porque,

148 Ramón Alberto Serna I. 
a excepción de los recursos naturales, que son transformados en materias primas para la industria, los demás bienes y servicios ambientales no se comercian en los mercados, ocasionando que los niveles de utilización e impacto sobre los recursos sean mayores que si la apropiación se realizara mediante el sistema de precios.

Se asume la preferencia individual por bienes como agua limpia, aire puro, visibilidad del paisaje, ausencia de ruido y congestión de tráfico, entre otros. El problema económico surge porque la escasez de estos recursos y la satisfacción de las preferencias está sujeta a restricciones de ingreso y desigualdades de riqueza. En respuesta a ello, se plantean soluciones orientadas a maximizar el beneficio social, para las generaciones actuales y futuras, en la asignación de recursos escasos. Sin embargo, no es claro el número de generaciones futuras que deben ser consideradas para la asignación intertemporal de recursos. Además, estas técnicas de análisis de costo-beneficio, debido a su difícil evaluación, pueden facilitar la distorsión de los resultados en favor de los que prefieran los profesionales. Algunas de las críticas con mayor fundamentación que se hacen a estas metodologías recaen sobre el hecho que asumen que los sistemas ambientales pueden ser abordados como divisibles; que para los mismos es posible lograr una posición de equilibrio; que muchos de los cambios de los sistemas ecológicos son potencialmente reversibles, entre muchos otros aspectos a resolver.
Hacia los primeros años de la década de 1960, existía gran optimismo para la innovación, ya que los métodos científicos habían demostrado gran solvencia para la resolución de problemas técnicos en el mundo físico y biológico y prometían un resultado similar en el mundo social. Al parecer, lo único que faltaba era encontrar un lenguaje que tradujese el medio creado por el hombre en los términos propios del medio natural y que la estructura espacial proporcionaría uno de estos lenguajes y el análisis de sistemas otro (Haggett \& Chorley, 1989 citado en Unwin, 1995). Con esta base que aportaron los análisis espaciales y la teoría general de sistemas y debido a que la cuestión ambiental es de carácter eminentemente social (Leff, 1994), se plantea la necesidad de pensar los problemas ambientales de otra manera, ya que en ellos confluyen múltiples procesos cuyas interrelaciones conforman la estructura de un sistema que funciona como una totalidad organizada, es decir, constituyen un sistema complejo (García, 1994).

Tampoco es fácil establecer una clara relación entre una determinada utilización del medio ambiente y su consecuencia sobre el nivel de bienestar social. Los cambios en los niveles de beneficio social derivados del deterioro o de la protección ambiental, se utilizan para representar el valor de los bienes y servicios ambientales (Contraloría General de la República, 1994). 
Este carácter valorativo de la sostenibilidad hace que sea muy importante identificar el (los) contexto(s) relevante(s), que permitan una comprensión íntegra de la situación, dentro de los cuales se identifican contextos según los objetivos, v.g., ecológicos, biológicos, económicos, recursos, supervivencia y sociales (Dovers, 1989) o dentro de un contexto organización podemos mencionar los contextos espaciales, temporales, sectoriales, culturales, políticos y probabilísticos (según el riesgo aceptable en el diseño de un futuro sostenible).

Como contextos relevantes, aplicables a situaciones específicas (o combinaciones de ellas), que permiten una comprensión íntegra de la situación, se pueden identificar (Dovers, 1989):

Contextos de los objetivos (p.e. lo que queremos):

1. Ecológico - sistemas de soporte básicos de la vida.

2. Biológico - mantenimiento de la diversidad.

3. Económico - estabilidad en el sistema total que aporta bienes y servicios.

4. Recurso - provisión de bienes y servicios individuales (o equivalentes).

5. Supervivencia - necesidades humanas básicas.

6. Social - necesidades humanas intangibles y sustento.
Contexto organizacional (p.e. como llegamos allí):

7. Espacial - global, nacional, regional, local o familiar.

8. Temporal - horizontes relevantes en el tiempo.

9. Sectorial - identificación de sectores o recursos críticos.

10. Cultural - identificación de características y sensitividades de grupos en la sociedad.

11. Político - reconocimiento/recreación/ mantenimiento de estructuras organizacionales e institucionales requeridas.

12. Probabilidad - grado de riesgo aceptable en el diseño de futuros sostenibles (p.e. conservatismo innato, cuanta información se requiere, etc.).

Una diferencia relevante entre sistemas no sostenibles y aquellos que sean significativamente más sostenibles, es una mayor (y más rápida) obediencia a las restricciones ecológicas y la sensitividad a los sistemas naturales. Esta obediencia asegurará la creación de patrones de producción y consumo que son más sensitivos a la información, lo cual permite una respuesta más correcta a las restricciones ecológicas. Sin embargo, la situación siempre se presentará en donde se requieran decisiones y acciones bajo información imperfecta. Este es el caso que ocurre con aspectos como el cambio climático y la biodiversidad. Esto deman-

150 Ramón Alberto Serna I. 
da de la sociedad claridad sobre la forma en que deben tomarse las decisiones sobre la base del conocimiento que se posee (contexto 12 - probabilidad).

De esta manera, la sostenibilidad sólo puede significar algo útil para la formulación de políticas una vez que se haya identificado un contexto específico.

\section{Desarrollo sostenible como legado} al futuro

Se pueden distinguir dos puntos de vista (Universidad Javeriana s.f.):

a) La compensación para el futuro se consigue asegurando que las actuales generaciones dejen a las siguientes con al menos el mismo capital que heredaron. El supuesto implícito es que el capital hecho por el hombre y el natural son mutuamente sustituibles.

b) La compensación para el futuro debería enfocarse no sólo en el capital hecho por el hombre, sino también debería prestar especial atención a la riqueza ambiental. Esto es, las generaciones futuras no deben heredar menos capital ambiental que el que heredaron las generaciones actuales. En este caso se enfatiza que la 'riqueza constante' debería buscarse evitando las irreversibilidades que generalmente toman la forma de pérdida de capital natural.

De manera alternativa se sugiere que no debería permitirse la disminución de los bienes naturales con el tiempo, ya que muchos de ellos no pueden ser sustitui- dos por bienes hechos por el hombre; existe incertidumbre sobre el comportamiento futuro de la tecnología y su potencial para poder sustituirlos; es peligrosa la irreversibilidad de la pérdida de bienes naturales y muy difícilmente involucra los bienes hechos por el hombre. Finalmente, estos aspectos no afectan de manera idéntica a naciones ricas y pobres.

De lo anterior puede notarse que el concepto de 'riqueza constante' dentro del desarrollo sostenible está sujeto al riesgo de manipulación política y deben desarrollarse formas de medir el desarrollo que involucren cambios en los bienes ambientales y la calidad ambiental debe incidir de forma explícita en las decisiones de inversión.

\section{Importación y exportación de sostenibilidad}

Es probable que una nación asegure el desarrollo sostenible, al costo de la sostenibilidad en otro país, evento que sucede cuando una economía importa materiales brutos, usa tecnología y habilidades humanas autóctonas para obtener productos finales con alto valor agregado y luego exportar.

El 'stock' de recursos naturales de esta nación permanecerá intacto, pero las naciones de las que importa pueden sufrir disminución en su capital natural, situación que sería sustentable si las ganancias de exportación fueran convertidas en inversiones que soportaran el futuro. El caso frecuente es que estas se transforman en consumo y no en base de capital. 
Mientras que la no sustentabilidad en los países exportadores debe ser parcialmente un asunto de decisión política, hay necesidad de devolver la sustentabilidad a las naciones exportadoras por medio de la ayuda ambiental. Tal ayuda debe asegurar el manejo sustentable de los recursos en las naciones exportadoras (Universidad Javeriana, s.f.).

\section{Ambiente, desarrollo y crecimiento}

Aunque mejorar la calidad ambiental puede aportar al crecimiento y al desarrollo, los costos de mejorar el ambiente pueden disminuir el crecimiento económico, si este es evaluado mediante los índices tradicionales. Sin embargo, el crecimiento no necesariamente implica degradación ambiental.

Los materiales se gastan en todos los procesos económicos y como son finitos, por definición, cuanto mayor sea el crecimiento, más rápido será el agotamiento. Aunque muchos materiales pueden ser reciclados mediante la reinyección en el sistema económico, con lo cual se reducen las demandas de materiales 'vírgenes', dicho reciclamiento posee un límite debido a la disipación de muchos usos (Universidad Javeriana, s.f.). Por el contrario, la energía no puede ser reciclada, ya que una vez utilizada se disipa y es por lo tanto necesario diseñar productos de bajo consumo de energía y racionalizar su uso.

Por ello, se plantea que hacia el futuro no es el desgaste de material y de recursos energéticos lo que constituirá un factor relevante, sino será el recurso del ambiente natural como depósito de todos los productos de desecho asociados con el uso de materiales y energía. Son las características de sumidero del ambiente las que quizá ocasionan la mayor preocupación. El reciclamiento, rediseño de productos, conservación y tecnología de bajos desperdicios pueden interrumpir el flujo de los desechos a estos recursos, y esa es quizá la principal característica de la vía para un desarrollo sustentable del progreso económico (Universidad Javeriana, s.f.). De esta manera, el mensaje del desarrollo sostenible es que se necesita prestar mayor atención a las variables ambientales.

En ocasiones se restringe la acción gubernamental hacia la conservación de recursos y reducción de desechos debido a la preocupación por la pérdida de empleos, como resultado del mayor costo de algunos bienes y servicios, lo cual implica beneficios hacia empleos relacionados con patrones de producción y consumo que sean ecológicamente de mayor sostenibilidad (Centro de las Naciones Unidas para los Asentamientos Humanos, 1996).

\section{La huella ecológica de las ciudades}

Todas las ciudades se basan en recursos naturales producidos fuera de sus áreas construidas. El área total de tierra requerida para sostener una ciudad, llamada la huella ecológica, se ha estimado en ser generalmente del orden de diez veces la

152 Ramón Alberto Serna I. 
del área incluida al interior de la ciudad o dentro del área construida asociada, lo que implica que las ciudades se apropian de la capacidad de soporte de otras áreas. Esta capacidad de soporte se define como la población de una determinada especie que puede ser sustentada indefinidamente en un hábitat dado, lo cual implica la conservación del ecosistema que sirve como sustento. Para el caso de las ciudades, esta puede ser interpretada como la máxima tasa de consumo de recursos y descarga de desechos que puede ser sostenida indefinidamente por una región sin deteriorar la integridad funcional y la productividad de los ecosistemas involucrados (Rees, 1992 citado por Centro de las Naciones Unidas para los Asentamientos Humanos, 1996).

Una ciudad con desarrollo sustentable debería tener un intercambio de bienes y servicios cuyos flujos de materia y energía no alteraran el capital de recursos naturales que le da sustento, ya fuera en su sitio de asentamiento o en la región donde ejerce su influencia. Por desgracia, sólo una ciudad que violara las leyes de la termodinámica y operara con máquinas en perpetuo movimiento podría cumplir con este principio (Lacy, 1996). Además, la lógica económica y los acuerdos prevalecientes ignoran la capacidad de soporte, ya que el libre intercambio de bienes y servicios ecológicos sin restricciones a la población o al consumo, garantiza la absorción de los superávit, con lo cual estimula a todas las regiones a acceder su capacidad de carga local, con el consiguiente incremento en el riesgo a largo plazo (Rees, 1992 citado por Cen- tro de las Naciones Unidas para los Asentamientos Humanos, 1996).

Algunas medidas que pueden reducir la huella ecológica en la ciudad incluyen (Centro de las Naciones Unidas para los Asentamientos Humanos, 1996):

* Incremento en la producción de biomasa en la ciudad o en su entorno inmediato (árboles, cosechas, peces). En este sentido tienen gran lógica las propuestas de corredores biológicos para el POT de Bogotá por la CAR.

* Reducir los desechos o aumentar el uso de estos como insumo para la producción (abonos orgánicos, agua de desecho para la agricultura urbana -debe considerarse que una proporción importante de frutos, vegetales y algunos otros cultivos consumidos en la ciudad son producidos dentro de las fronteras metropolitanas o justo por fuera de ella-; implementar la recuperación y reciclaje de materiales). Como las cooperativas de recicladores en Bogotá.

* Mejora en la eficiencia en el uso de recursos importados a la ciudad (agua dulce, combustibles fósiles, recursos minerales). Puede mencionarse el enfrentamiento entre la CAR, el DAMA y el Distrito en relación con el crecimiento de la ciudad incrementando la densidad urbana propuesto por la primera entidad, lo cual mejoraría la eficiencia en el uso de recursos naturales y energéticos que ingresan a la ciudad, en contraposición con las últimas entidades que proponen una urbanización dispersa, lo cual iría en detrimento de los recursos, pero 
incrementaría la renta de las zonas de expansión.

La importancia de la agricultura urbana ha sido poco comprendida por las autoridades de la ciudad o por los investigadores (Centro de las Naciones Unidas para los Asentamientos Humanos, 1996). Esta es una actividad que puede combinar objetivos ambientales como la disminución de la huella ecológica y permite utilizar los desechos de las ciudades con objetivos sociales y económicos, generando empleos y contribuyendo a la alimentación o los combustibles requeridos por grupos de bajos ingresos. De la misma manera permite usar tierra que difícilmente será empleada con otros propósitos (tierras bajo líneas de alta tensión, sitios con riesgo de inundación o vacantes), así como reducir los insumos energéticos para la producción y distribución de alimentos al reducir la distancia entre la producción y el consumo.

Hacia la reducción de la huella ecológica, apuntan alternativas como la disminución en el uso de combustibles fósiles en el transporte, promoviendo desarrollos urbanos relativamente densos alrededor de nodos de transporte público que estimulan patrones de desarrollo mixtos.

Aunque en repetidas oportunidades se plantea que la densidad urbana es la causa de la contaminación y la congestión, ésta puede deberse más al atraso de la red vial, que para Bogotá es del $40 \%$ y el del parque automotor de vehículos particulares con un promedio de 12 años y de 16 años para el transporte público
(Vasco y Pérez Preciado, 2001). Esto no puede significar sacar este parque de funcionamiento como es usual en el mundo, sino mejorar las técnicas de adecuación que permitan incrementar la vida útil, lo cual plantea un desplazamiento de patrones consumistas a otros basados en el reciclamiento. La mayor concentración de partículas en suspensión está hacia el sur (en este aspecto es importante recordar que hacia las zonas de Soacha y Mondoñedo, están las áreas de menor precipitación de la Sabana, lo cual, obviamente incide en este aspecto). Otro factor que agrava el problema es el ingreso anual a la ciudad de 30.000 a 40.000 vehículos, lo que tiene gran impacto, por lo cual debe desestimularse el uso del automóvil privado, concomitante con el mejoramiento en las iniciativas de transporte masivo. Para el caso del proyecto de Transmilenio en Bogotá, sería interesante evaluar el impacto de esta iniciativa.

El costo económico y ecológico para las regiones como resultado de la demanda urbana por recursos rurales, la contaminación y la expansión desordenada de la ciudad son resueltos en muchas ocasiones de mejor forma al actuar sobre la ciudad, p.e. al controlar la contaminación y reducir los desechos dentro de la ciudad. Otros problemas como la pérdida de tierras agrícolas, destrucción de paisajes naturales, espacios públicos abiertos y los costos ecológicos inherentes al crecimiento urbano de baja densidad, necesitan un control público que permita resolver conflictos entre los objetivos económicos, sociales y

154 Ramón Alberto Serna I. 
ecológicos (Centro de las Naciones Unidas para los Asentamientos Humanos, 1996).

Aunque la definición de la huella ecológica puede tener consenso entre especialistas en ciencias ambientales, deja de lado aspectos como la democratización de la ciudad, su gobernabilidad, la seguridad ciudadana, o la forma como debe fortalecerse la administración comunitaria o estatal, aspectos que serían considerados como parte del desarrollo sustentable por sociólogos, políticos y urbanistas.

Sin embargo, irónicamente, muchas de las ciudades del 'Sur', cuyas condiciones de vida y niveles de vivienda son malos, constituyen modelos de 'sostenibilidad ecológica', debido a que los niveles de uso de recursos y generación de desechos son bajos, al tiempo que muchos de ellos son reciclados, lo cual manifiesta ingresos muy inadecuados para una alta proporción de la población. En ocasiones, las autoridades urbanas buscan introducir objetivos sociales y ambientales en la recolección y gestión de desechos sólidos, como en Bogotá, en donde los recicladores han formado cooperativas que han licitado con éxito contratos de recolección de desechos municipales (Pacheco, 1992 citado por Centro de las Naciones Unidas para los Asentamientos Humanos, 1996).

\section{Localización de las actividades económicas y sostenibilidad}

La ciudad, como centro de acumulación de poder, producción y población, genera, entre otros, una gran centralización como sumidero energético y por lo tanto presenta un gran potencial para degradar el medio ambiente. Por ello, es importante analizar brevemente los factores de localización de las actividades económicas (tabla 2) y su incidencia sobre la sostenibilidad de las ciudades. 
Tabla 2

Factores de localización de las actividades económicas

\begin{tabular}{|c|c|}
\hline FACTORESECONÓMICOS & FACTORESEXTRAECONÓMICOS \\
\hline $\begin{array}{l}\text { 1. Costos e ingresos de las empresas } \\
\text { - Costes de transporte/comunicación } \\
\text { (con proveedores y clientes) } \\
\text { - Costos de producción: } \\
\text { - Costos de emplazamiento de la empresa } \\
\text { - Salarios (directos e indirectos) } \\
\text { - Capital } \\
\text { (fijo y variable, incluidos insumos) } \\
\text { - Tamaño y características del mercado } \\
\text { de consumo (final y/o empresarial) } \\
\text { 2. Externalidades } \\
\text { - Economías externas (de localización y } \\
\text { urbanización) } \\
\text { - Deseconomías externas }\end{array}$ & $\begin{array}{l}\text { 1. Percepción empresarial } \\
\text { - Limitaciones informativas } \\
\text { - Procesos de decisión en organizaciones } \\
\text { - Características internas de las empresas } \\
\text { - Calidad del medio ambiente } \\
\text { (natural y social) } \\
\text { - Inercia espacial } \\
\text { 2. Factores sociales y políticos } \\
\text { - Relaciones sociales y organización } \\
\text { - } \text { sindical } \\
\text { - Redes de cooperación } \\
\text { (formales e informales) } \\
\text { - Marco legislativo } \\
\text { - Políticas públicas de promoción, } \\
\text { ordenación territorial y medio ambiente }\end{array}$ \\
\hline
\end{tabular}

FUENTE: Méndez, 1997, modificado.

Uno de los primeros criterios que guía la localización, es el intento de reducir los costos de producción, transporte y transferencia de mercancías, personas e información. Las mejoras técnicas en transporte y telecomunicaciones, provocan desvalorización del factor distancia, ya que el costo no es proporcional a la distancia lineal recorrida por un bien o servicio, sino que depende en mayor grado de operaciones de carga/descarga, con flujos más diversificados según las características de cada medio (Méndez, 1997). Esto incrementa las posibilidades de exportar sostenibilidad y hace de las ciudades sistemas cada vez más abiertos, más dependientes de factores externos y por lo tanto con una menor capaci- dad de controlar y mantener su funcionamiento dentro de límites homeostáticos que permitan garantizar la sostenibilidad del sistema. Se espera, por lo tanto, para poder responder adecuadamente a estos retos globalizantes y en gran medida desestructurantes, que estos sistemas adopten estructuras flexibles, de funcionamiento descentralizado que permitan amortiguar las externalidades.

De la misma forma, y con el fin de garantizar una mayor sostenibilidad, es conveniente un mejor ajuste a las condiciones medioambientales de la ciudad, lo cual no significa una visión determinista de las relaciones entre la ciudad y el medio ambiente, sino que se debe promover que

156 Ramón Alberto Serna I. 
el valor de los bienes y servicios refleje el costo de producción (incluido el medio ambiente). Sin embargo, por esta vía nuevamente llegamos a la inequidad que supondría el acceso a bienes y servicios 'costosos'. Así, se refrenda la equidad como requisito 'sine qua non' para abordar nuevas discusiones sobre la sostenibilidad y que debe estar por lo tanto implícita en todo el proceso productivo. La equidistribución (especialmente en las oportunidades de acceso a los bienes y servicios), implica una disminución de la maximización de las ganancias y por lo tanto es necesaria la intervención del Estado.

El supuesto de movilidad perfecta para el capital líquido o monetario que se desplazaría a lugares con razonables expectativas de beneficio, ha reducido su importancia como factor de localización, y en cambio ha ganado mayor importancia la acumulación histórica de capital fijo en ciertos territorios, bajo la forma de infraestructuras (aeropuertos, redes telefónicas, saneamiento, etc.), equipamientos (universidades, hospitales, viviendas, parques industriales, etc.) y bienes de equipo (instalaciones productivas, maquinaria, etc.) (Méndez, 1997). Estos factores de crecimiento acumulativo de áreas ya desarrolladas que pueden atraer nuevas inversiones $\mathrm{e}$ incrementar la rentabilidad actual, constituyen tendencias retroalimentadoras que pueden conducir a un incremento de la entropía y al colapso e inviabilidad del sistema por saturación (sensu Flórez y Thomas, 1993).
Ciudades en países periféricos sin dicha acumulación histórica de excedentes, necesaria para impulsar inversiones futuras, incentivan la localización de empresas mediante el abaratamiento de los costos a partir de subvenciones, exenciones fiscales, créditos de bajo interés o disminuyen las restricciones al funcionamiento de actividades altamente contaminantes (Méndez, 1997), con un elevado costo social y ambiental en el proceso productivo que no es evaluado debidamente y cuyos beneficios son exportados. Esta laxitud normativa, puede conducir en el tiempo a un desgaste y depreciación de capital, por obsolescencia de la infraestructura y los procesos productivos con costos cada vez más crecientes.

Una adecuada valoración del territorio por las empresas puede favorecer una elevada calidad de vida y facilitar un funcionamiento eficiente (Méndez, 1997). Por el contrario, la no valoración del medio ambiente en los procesos de producción, ha conducido a bajos índices materiales de muchos bienes y servicios generados en Latinoamérica, los cuales han coadyuvado al deterioro ambiental y la getthización de cinturones periféricos informales en las ciudades.

Las externalidades, efectos positivos o negativos, ocasionados por actividades $o$ empresas sobre otras del entorno y que provocan aumento o disminución en el nivel de eficiencia y/o utilidad (Méndez, 1997), constituyen factores explicativos importantes de la exportación de la 
sostenibilidad como se abordó en un apartado anterior. Acá es relevante la importancia del principio de la equidad en la distribución de las cargas y beneficios. En nuestros países es usual que las externalidades negativas no sean asumidas por las empresas, dejando sus efectos a la comunidad o al Estado, mientras que los beneficios de las externalidades positivas si son reclamadas por las empresas. Es por ello que, colindante a las expectativas de beneficio que conforman economías externas de acumulación, se generan economías informales de localización. Después de determinado nivel de beneficio, cuando los costos empresariales se incrementan (por aumento en el valor del suelo, mano de obra, normatividad más exigente, etc.), se promueve la relocalización de algunas actividades empresariales, promoviendo deseconomías externas de aglomeración, que no necesariamente se traducen en una disminución de la carga sustentable de la ciudad.

Aunque esta proximidad espacial con algunos desarrollos empresariales propicia intercambios de conocimiento e información que pueden generar el aprendizaje colectivo, la interacción y promocionar la aparición de medios innovadores altamente dinámicos, acompañado de beneficios a las empresas derivados de las economías de urbanización por las mejores condiciones de dichos espacios, alta valoración social y menor sensación de riesgo (Méndez, 1997), dicho proceso es altamente selectivo, inequitativo y segregacionista. La baja capacidad organizativa de las comunidades es otro factor que permite una mayor manipulación social por las empresas y que va en detrimento de la sostenibilidad al interior de la ciudad.

A diferencia de lo planteado por la teoría de localización economicista que ha dominado ampliamente, las decisiones empresariales de localización son imperfectas, ya que la información disponible siempre es parcial y selectiva, según valoraciones subjetivas (Méndez, 1997). Por ello, cobra gran importancia lo local y sus estrategias adaptativas culturales como factor de planificación orientada a promover un desarrollo sostenible, el impulso a las microempresas; proceso que debe ser crítico frente a la inercia espacial y a la comprensión de la estructura urbana.

\section{El desarrollo sostenible y las metrópolis latinoamericanas}

Cuanto más grande y poderosa es una ciudad, mayor es su dependencia de insumos externos y la alteración de su entorno inmediato, constituyéndose en sumideros de energía con intercambios desventajosos para el medio rural. Además del aspecto netamente ambiental, el desarrollo sostenible en la ciudad debe considerar aspectos como la democratización de la ciudad, su gobernabilidad, su equidad o la seguridad ciudadana y se deben identificar y controlar las tendencias entrópicas, aceptar pérdidas ambientales y sociales, negociarlas y estimular la participación ciudadana. Sin embargo, es claro que el cambio de actitud cultural

158 Ramón Alberto Serna I. 
necesario para transformar la sociedad derrochadora y consumista en una que posea patrones de consumo razonado avanza lentamente con una inercia que puede durar décadas (Lacy, 1996), por lo cual el énfasis del desarrollo debe centrarse en la organización colectiva de la mente humana y su capacidad para proyectarse en la realidad (Tudela, 1996).

Aunque las ciudades grandes, pueden favorecer procesos de crecimiento acumulativo en favor de áreas ya desarrolladas, generando beneficios de economías de escala, en nuestro medio, la evidencia muestra que a medida que se incrementa el tamaño de una ciudad, decrece su eficiencia por factores restrictivos relacionados con la infraestructura de servicios, mayores problemas, etc.

La transformación de nuestras ciudades presenta tres ámbitos: el cultural que afecta nociones de ciudadanía, conciencia, educación y liderazgo; el modelo de funcionamiento económico de la sociedad y el de la sustentabilidad ambiental que implica la recuperación y sostenimiento de equilibrios ecológicos en contextos de fuerte intervención humana y creación de ambientes 'artificiales' (Carrión, 1996). Así mismo, debe atenderse a la segregación funcional de las ciudades que conducen a grandes demandas de transporte y al consumo excesivo de espacio en los procesos de urbanización (Tudela, 1996).

En la actual discusión sobre gobernabilidad, ejercida a través de la planificación urbana, subyacen incuestionados y quizás inconscientes ocultos y discutibles valores de expresiones de deseos y falacias, como la supuesta validez universal de la racionalidad del saber técnico, que tiende a ser identificado con la verdad, y que por lo tanto justifica que el estamento técnico-profesional sea el proveedor legítimo de las pautas y orientaciones que deben seguir los gobernantes en sus decisiones (tecnocracia) y el considerar al Estado como poseedor de una alta capacidad para determinar el comportamiento de los actores sociales, generando ambientes neutros en relación con los intereses en juego y las relaciones de poder que se generan en el mercado y la sociedad civil, cuando en general los gobiernos y sus administraciones no operan neutralmente, sino que generalmente establecen alianzas y oportunidades en favor de los intereses más poderosos en cada escenario (Robirosa, 1996).

La participación ciudadana todavía es tratada con gran ingenuidad. Aunque se recomiendan acciones educativas como formadoras de una conciencia socioambiental y de la capacidad de diagnóstico y demanda de los sujetos sociales, al tiempo que se espera que dicha movilización participativa sea escuchada, debe tenerse en cuenta que la sociedad es un complejo de actores tremendamente heterogéneos, tanto en intereses como en escenarios de acción (Robirosa, 1996).

En Colombia en años recientes se ha dado un gran impulso a la acción ambiental, concomitante con cambios institucionales que estimulan la acción y participa- 
ción local. Entre ellos está el proceso de descentralización planteado por la Constitución de 1991 y la creación del Ministerio del Medio Ambiente en 1993. Para el caso de Bogotá, esto se ha manifestado en el desarrollo de las agendas ambientales, apoyadas por el Departamento Administrativo del Medio Ambiente (DAMA), las ONG y académicos. Estas agendas permiten identificar y atender problemas ambientales, constituyendo un insumo importante para la planeación de la ciudad. El primer paso consiste en desarrollar un perfil ambiental en el que se identifican recursos y problemas ambientales y se localizan dentro de la estructura física y socioeconómica de la localidad. En el segundo paso se definen las agendas locales, con programas y proyectos prioritarios, responsabilidades financieras de las organizaciones involucradas y cronograma de inversiones. De la misma manera se establecen asociaciones entre los Consejos Administrativos Locales y las organizaciones de base comunitaria, las ONG y otros grupos locales. Esta mayor atención a los asuntos ambientales también está siendo apoyada por una mayor prioridad de lo ambiental en la educación (Pacheco Montes, s.f. citado por Centro de las Naciones Unidas para los Asentamientos Humanos, 1996).

Sin embargo, la gestión ambiental está fuertemente permeada por relaciones de poder, como queda evidenciado, por ejemplo, en el Plan de Ordenamiento Territorial de Bogotá (POT), en el cual contrastan las posiciones de diferentes entidades. P.e., la CAR plantea un crecimiento urbano de mayor densificación, basado en los actuales bajos índices de construcción dentro de zonas urbanas consolidadas (actualmente la densidad es de 210 habitantes/ha y 56 viviendas/ha; lo cual es bajo si se compara con otras ciudades, p.e. Londres con 247 habitantes/ha, (Vazco y Pérez Preciado, 2001) y confía en la capacidad del Estado para intervenir acertadamente en dicho proceso. Por otra parte, la intención del Distrito es 'dispersar' población por la Sabana, hacia el polo urbano constituido por San Simón (ubicado entre la zona de Guaymaral y límites con el municipio de Chía) y alrededores del eje de la Autopista Norte, lo cual tendría unos costos ambientales y de infraestructura muy altos, así como marcados cambios económicos implicados en la declaración de estas áreas como zona de expansión urbana y alrededor de la cual giran múltiples intereses. En este aspecto no hubo concertación entre las entidades y por ello fue necesaria la intervención por parte del Ministerio del Medio Ambiente.

Concomitante con este litigio aún en boga, el contexto está permeado por la valoración ambiental que hace la sociedad. Mientras algunos plantean que la zona norte de Bogotá no pasa de ser un 'kikuyal para vacas', otros valoran adecuadamente el patrimonio a conservar, ya que están los mejores suelos agronómicos, son abundantes los humedales, constituye una zona de inmenso valor paisajístico, con algunos recursos hídricos y es una zona de recarga de acuíferos (Vazco y Pérez Preciado, 2001).

160 Ramón Alberto Serna I. 
En este punto puede resultar esclarecedor recordar lo que ocurrió con el lento poblamiento del caserío de Chapinero (actualmente un sector no periférico de Bogotá), hacia finales del siglo XIX, que como zona urbana algo retirada de Bogotá, llegó a pensarse que podría convertirse en una gran ciudad que rivalizaría con ésta. Sin embargo, la fundación del templo de la Virgen de Lourdes en 1892 (Iriarte, 1988), promovió la consolidación de la estructura urbana a través del eje vial que comunicaba con este núcleo.

Nuevamente, debido a aspectos valorativos, el desarrollo sustentable no debe entenderse en este caso como un estado final de equilibrio ecológico, sino como transición hacia estados de racionalidad creciente que trasciende los ámbitos biofísico, económico o político y que espacialmente hace menos importante la delimitación de la 'mancha urbana', ya que muchos procesos productivos 'rurales' sólo pueden explicarse por la demanda urbana. De la misma manera trascienden el marco temporal, al involucrar los intereses de las generaciones futuras y su incapacidad de manifestarse en los mercados actuales (Tudela, 1996).

La anterior ampliación analítica conlleva el peligro de enfoques de holismo o idealismo descontrolados. Por ello, para hacer operativamente funcional el concepto de desarrollo sustentable, es necesario simplificar cada problema tanto como sea productivamente posible y reconocer que la gestión pública sólo puede operar en la actualidad al sectorizar la realidad. La transición hacia un desarrollo urbano sos- tenible parte del reconocimiento de la escasez, en cuanto a la determinación de umbrales, topes, límites y exige la organización del imaginario colectivo que debería constituir la principal tarea de los partidos políticos (Tudela, 1996).

\section{Urbanización y desarrollo sostenible}

La espacialidad latinoamericana presenta una serie de rasgos que permiten abordar aspectos relacionados con la sostenibilidad urbana. Según Samuel Jaramillo (s.f.) pueden destacarse los siguientes aspectos espaciales como característicos:

a) Una tendencia muy rápida a la urbanización, proceso asociado a importantes corrientes migratorias rural-urbanas. Según el sociólgo brasileño Paul Singer el campo constituye un polo de expulsión. Hay factores de atraso que involucran la productividad, la venta de la fuerza de trabajo y el factor de modernización dado por nuevas relaciones sociales en el campo como las ocasionadas por la entrada de maquinaria, etc., que generan la salida hacia los polos de atracción. Para el caso colombiano, este proceso se incrementa por la violencia como factor de expulsión (y que no es tenido en cuenta por Singer). Sin embargo, estos procesos de urbanización han sido promovidos como políticas estatales dentro de los Planes de Desarrollo, como sucedió con el Plan de las Cuatro Estrategias (19701974), mencionado anteriormente.

b) Desarticulación de la red urbana. La estructura espacial aparece más como un 
obstáculo que como apoyo al desarrollo social. Esto se manifiesta como una excesiva primacía de la ciudad más importante, por lo cual se habla de macrocefalia urbana, acompañada de hiperconcentración de la población urbana e hiperurbanización, perjudiciales al desarrollo urbano.

c) Persistencia de diferencias regionales muy marcadas. El territorio presenta una débil integración e interdependencia, lo que restringe las posibilidades de la cooperación; así mismo, perviven zonas extensas prácticamente deshabitadas e inexplotadas y otras sobrepobladas e hiperdensas.

d) Enorme distancia social entre el campo y la ciudad, que obstaculiza la complementariedad del territorio.

e) Agudeza excepcional de la segregación socioespacial. Los distintos sectores territoriales de la ciudad parecen operar con lógicas muy heterogéneas.

f) Existencia en las ciudades de importantes y crecientes contingentes de población desempleada o no articulada laboralmente de manera directa al capital. Esto genera dinámicas sociales y espaciales muy peculiares.

g) Presencia en las grandes ciudades de rasgos 'tradicionales', normalmente asociados a un marco ecológico rural. Físicamente aparecen en las ciudades configuraciones y formas de producción, al igual que comportamientos y valores de tipo rural; por ello se habla de ruralización de las ciudades.

h) Baja provisión de valores de uso colectivo urbano. Se crea un gran desequilibrio espacial y social en el suministro de estos valores.

i) Debilidad de los aparatos administrativos locales. Está relacionado con limitaciones financieras y dificultades políticoadministrativas, lo que se traduce en el desarrollo de prácticas con pocas mediaciones y conduce a procesos de urbanización espontánea, desorden urbano, etc.

La Teoría de la Marginalidad constituyó la primera formulación de la urbanización latinoamericana como algo específico y proviene de una extensión de la Sociología Urbana Norteamericana positivista. La tesis central, encaminada a explicar la 'ruralización de las ciudades', descansa en el reconocimiento en las ciudades latinoamericanas de barreras culturales que impiden el paso expedito de lo tradicional a lo moderno. De esta forma, muchos habitantes son marginados del desarrollo y el progreso, procesos que son en gran medida originados por inducción externa, a diferencia del que se observa en los países avanzados, en donde ocurre por autogeneración (Jaramillo, s.f.).

Esta explicación presenta dos corrientes principales, con desarrollos y planteamientos políticos diferentes. Una versión 'de derecha' de esta Teoría, plantea la necesidad de limar estas asperezas que considera de tipo inercial y que obstacu-

162 Ramón Alberto Serna I. 
lizan la modernización. La acción política se centró en la eliminación de estos reductos de ruralidad, para lo cual, en la década de los cincuenta y sesenta, muchas ciudades iniciaron programas de 'erradicación de tugurios', con adaptación de estos grupos marginales a las exigencias de la sociedad moderna (Jaramillo, s.f.). En esta perspectiva se pierde el valor de las adaptaciones culturales y simplemente se pretende abolir estas 'rugosidades', sin ninguna posibilidad de promover procesos equitativos de desarrollo.

La versión 'de izquierda' plantea que la marginalidad es ocasionada por la negación de los grupos privilegiados a renunciar a ninguna de sus ventajas y a la incapacidad del Estado de enfrentar estos intereses. Propone el ingreso a la modernización a través de facilidades de educación, adiestramiento laboral y participación política de los marginados; así como extender al campo las ventajas urbanas, combatir la marginalidad rural vía el incremento de la inversión estatal y una reforma agraria que estimule la permanencia en el campo. Considera los asentamientos populares como una respuesta ingeniosa y eficiente a las condiciones desfavorables y potencia el uso de recursos de estos grupos, valora la mano de obra, al tiempo que permite flexibilizar los flujos de fondos, ofreciendo mayores ventajas que los planes gubernamentales. De esta forma, la 'urbanización popular' es considerada un poderoso mecanismo de promoción social y de adaptación de los migrantes a la ciudad y propone encauzar y apoyar estos procesos (Jaramillo, s.f.). De esta manera se rescatan muchos elementos que pueden promover un desarrollo sostenible.

Posteriormente, la Teoría de la Urbanización Dependiente surge como reacción frente a la Teoría de la Marginalidad, en los años sesenta y comienzos de los setenta. Propone la interpretación marxista que fija la atención en las relaciones de clase como motor del desarrollo de la sociedad, en las cuales son importantes la explotación económica y la opresión política. Considera que estas 'anomalías' observadas en el supuesto retraso de la urbanización-modernización, son en realidad resultado de estructuras diferentes, conectadas con el carácter dependiente de la acumulación latinoamericana y por lo cual recibe dicho nombre (Jaramillo, s.f.).

Considera que la configuración de la estructura espacial latinoamericana obedece al despojo y opresión por parte de los países centrales y que esta asimetría entre países se reproduce al interior, entre secciones centrales y periféricas. Diferencia periodos de dependencia colonial, cuando los territorios latinoamericanos formaban parte de los imperios español y portugués; un periodo semicolonial que coincide con la disolución del imperio español en América y mayor autonomía de las colonias portuguesas, caracterizado por la especialización en la fabricación de materias primas y productos agrícolas, con intercambio desigual por manufacturas de las nuevas metrópolis, principalmente en Inglaterra. Otra modalidad la constituyen las economías de planta- 
ción que requieren el empleo de mano de obra nativa, y ocasionan mayor impacto espacial que las estructuras previas, aunque dicho impacto se da principalmente en sectores urbanos vinculados al proceso productivo, como los centros de aprovisionamiento, tránsito y embarque, mientras que los vastos sectores vinculados a economías de subsistencia, presentan una evolución espacial muy lenta. Una última variante es de 'dependencia comercial', con economías agrícolas y ganaderas de exportación, sustentada en estructuras de producción relativamente atrasadas que generan abundantes excedentes y conducen a un gran desarrollo de la red urbana (Jaramillo, s.f.).

La fase más reciente de dependencia es denominada como 'industrialización por substitución de importaciones' (o 'neocolonia'), en el cual ocurre inversión directa del capital monopolista de los países centrales en sectores industriales ligeros de los países periféricos, orientado hacia el mercado interno de estos, lo cual ocasiona que gran parte del excedente salga del ámbito local a través de remisión de utilidades, pago de patentes, etc. (Jaramillo, s.f.). En las relaciones que se establecen por las formas de dependencia mencionadas, se exporta sostenibilidad hacia países centrales a costo de recursos de la periferia; situación aplicable también a la relación que se establece entre ciudades de diferente rango, en la cual, los núcleos periféricos asumen costos del desarrollo de las ciudades centrales.

La irrupción masiva de capital genera profundos cambios en la estructura, en parte debido al incremento demográfico ocasionado por una mejoría en las condiciones sanitarias de la población, ampliación de la economía mercantil debido a la vinculación de muchas regiones rurales que permanecían en una economía de subsistencia, y que ahora son presionadas hacia la 'modernización', con cambios en la propiedad de la tierra y que dan como resultado la expulsión de gran población excedente hacia las ciudades (Jaramillo, s.f.). Los patrones tecnológicos que requieren cada vez menos mano de obra, no pueden ser considerados como modernización, ya que conducen al fortalecimiento de la economía informal para poder subsistir.

En las ciudades, la industrialización avanza con gran monopolización y alto nivel de tecnificación, por lo cual se plantea que la única forma de eliminar los rasgos de la urbanización dependiente (macrocefalia urbana, barrios miserables, población urbana redundante), es romper con las determinaciones básicas, como la subordinación al capital imperialista (Jaramillo, s.f.).

Frente a esta situación, Jaramillo (s.f.) propone un análisis sustentado en el carácter capitalista de las formaciones sociales latinoamericanas, cuyo eje debe ser la comprensión de los procesos de acumulación. Además debe incluirse en el análisis el lugar subordinado de estos países en la cadena capitalista mundial, es decir, se debe recuperar la problemática dependentista. Sin embargo, debe ampliarse el concepto de dependencia, que para los teóricos de la TUD se refie-

164 Ramón Alberto Serna I. 
re casi exclusivamente al intercambio desigual y a las relaciones de poder asimétricas. Hoy se piensa en esta como una realidad que atraviesa las condiciones de acumulación en la periferia. Así mismo, se plantea la necesidad de considerar el ingreso actual del capitalismo en una fase monopolista avanzada. De hecho, las concepciones marxistas actuales consideran que el capitalismo se encuentra dominado por monopolios fundidos con el Estado y por lo cual exhiben una lógica espacial muy diferente a las fases anteriores, que se manifiesta de manera diferente en la periferia que en el centro y requiere una elaboración cautelosa.

Estos procesos de acumulación de capital contemporáneo están cada vez más ligados a rasgos propios de la aglomeración urbana, como es el caso de la producción de conocimientos e investigación, la gestión y la decisión, o la conformación de grandes complejos productivos resultantes de las relaciones interindustriales, etc. De esta forma, la ciudad pasa a ser el factor determinante de la localización industrial, a diferencia del proceso contrario que ocurría en la etapa anterior. El Estado suministra un conjunto de valores de uso colectivo (transporte, servicios públicos, infraestructura), que abrirán paso a la existencia de 'regiones metropolitanas' (Jaramillo, s.f.) y actúa en favor de garantizar mejores condiciones de mercado. Para el caso de Bogotá se plantea el inicio de la descentralización intrarregional como resultado de las desventajas de aglomeración dentro de un proceso de suburbanización (Mertins, 1998).

Para que ocurra la homogeneización del espacio originado por avances técnicos (difusión energética, redes de transporte, comunicaciones), se requiere gran acumulación de capital a nivel nacional, particularmente a través de la acción económica por parte del Estado. Como consecuencia de ello, en los países de la periferia se presenta concentración de las actividades productivas en núcleos especializados (Jaramillo, s.f.), cuyo acceso y beneficios son profundamente inequitativos.

La industria latinoamericana, con buen nivel en los adelantos técnicos, requiere utilizar fuerza de trabajo adiestrada, que es creada y reproducida en la gran ciudad, lo que se traduce en notorias diferencias de equipamiento entre la gran ciudad y el resto del territorio. Por otra parte, el crecimiento poblacional urbano, excede con mucho el lento crecimiento del empleo industrial, factor que está conectado en parte con las transformaciones inducidas por la nueva fase en el proceso de producción y por tanto esta incidencia es compartida con los países centrales (Jaramillo, s.f.). Esto genera enormes masas poblacionales con futuros inciertos y desesperanza cotidiana, para quienes surgen propuestas de desarrollo alternativo, como las de Desarrollo a Escala Humana (Manfred Max-Neef, 1998), las de Conocimiento y Práctica Política (Cardoso, 1998) y en general una serie de propuestas que implican una activa participación de las comunidades en 
la construcción de su propio destino (Fals Borda, 1998).

La llamada terciarización de la economía, caracterizada por una complejización de los procesos de consumo, de actividades ligadas a la reproducción de las fuerzas de trabajo, de procesos para-productivos como la gestión, la investigación, etc., se asienta preferencialmente en la gran ciudad, constituyendo un atractivo poderoso para amplios contingentes de población que engrosan los habitantes de la gran aglomeración (Jaramillo, s.f.).

El capital que opera en la periferia está sometido a condiciones de acumulación menos favorables y existe interacción con el resto del sistema que se manifiesta en competencia y/o movilidad del capital en la cadena del capitalismo internacional. Para que el capital se asiente en la periferia del sistema, debe contraer los costos salariales como principal 'ventaja comparativa', la cual se da gracias a un elemento convergente como es la superpoblación relativa. Para mantener la acumulación capitalista periférica, las diversas secciones de la ciudad deben funcionar de manera distinta, sobre una base de bajos salarios; muchos de los consumos, normalmente abastecidos por el mercado o por el Estado, deben ser suministrados en los sectores populares, generalmente bajo malas condiciones, por el mercado informal o son aportados por la comunidad misma (Jaramillo, s.f.). Así, es probable que con este tipo de propuestas, la voluntad política y económica conduzcan a la perduración de la tugurización de las ciudades, a procesos sostenidos de deterioro ambiental y social hasta alcanzar el umbral que separa el desarrollo sostenible del punto de no retorno que conduce a la ghettización, a una mayor generalización de la pobreza.

Otro móvil de atracción que se da en la gran ciudad sobre los grupos marginales o no, poco considerado en la tradición marxista, es el generado por una serie de valores de uso colectivo creados en la aglomeración urbana por el movimiento del capital, de cuyo consumo no pueden ser excluidos los grupos sociales y que están destinados a reproducir la fuerza de trabajo con las características que las condiciones actuales de producción exigen. Esto hace más soportable e incrementa las posibilidades de sobrevivencia social en la gran ciudad frente a otras localidades espaciales (p.e. los planes salubridad o ciertos servicios públicos) (Jaramillo, s.f.). Dado que estos instrumentos de planeación general para la ciudad han sido definidos a nivel urbano, lo que ha generado desarticulación de la ciudad ya que las necesidades o condiciones de los barrios que componen el tejido urbano recaen sobre los niveles vecinales, el Departamento Administrativo de Planeación de Bogotá, está implementando el uso de las Unidades de Planeamiento Zonal (UPZ), como instrumento que permita avanzar en el proceso de descentralización de la ciudad para construir una nueva estructura zonal, construida por la acción particular y la administración y que debe cumplir las directrices del modelo de ordenamiento territorial (Departamento Administrativo de Planeación, 2000).

166 Ramón Alberto Serna I. 
Retomando los elementos discutidos anteriormente, Jaramillo (s.f.), plantea que el exagerado crecimiento de la gran ciudad en Latinoamérica es explicado por cuatro elementos:

a) Combinación de factores 'nuevos' y tradicionales de localización industrial que tienden a centralizar marcadamente la actividad industrial en la gran ciudad.

b) Incremento de la importancia de las actividades 'terciarias superiores', centradas normalmente en la gran urbe.

c) Proletarización que incrementa el impacto poblacional de la reproducción de la fuerza de trabajo.

d) Diferencias en las condiciones de vida a favor de la gran ciudad, generadas por el movimiento del capital y que atrae sectores muy diversos.

Condiciones espaciales que contrastan con las de las ciudades en países avanzados (Jaramillo, s.f.):

a) La gran ciudad latinoamericana, pese a su tamaño, es puntual y focalizada, debido a la incompleta articulación espacial que no permite un funcionamiento metropolitano.

b) La proletarización que se da en los países periféricos, representa un grado muy agudo de explotación de la fuerza de trabajo, apoyado en gran medida en factores extrasalariales. Esto conduce a una fuerte segregación socioespacial.
Este mismo autor (Jaramillo, s.f.) plantea, a manera de hipótesis, que las 'regiones metropolitanas' en los países centrales y la 'gran ciudad primada' latinoamericana, son resultados espaciales derivados de transformaciones sociales que se dan en etapas avanzadas del capitalismo monopolista y cuyas diferencias están dadas por la inserción de la respectiva formación social en la red mundial de capitalismo.

Directamente relacionado con la función pública del urbanismo está el artículo 3 de la Ley 388 de 1997 que reza:

'El ordenamiento del territorio constituye en su conjunto una función pública, para el cumplimiento de los siguientes fines:

1. Posibilitar a los habitantes el acceso a las vías públicas, infraestructuras de transporte y demás espacios públicos, y su destinación al uso común, y hacer efectivos los derechos constitucionales de la vivienda y los servicios públicos domiciliarios.

2. Atender los procesos de cambio en el uso del suelo y adecuarlo en aras del interés común, procurando su utilización racional en armonía con la función social de la propiedad a la cual le es inherente una función ecológica, buscando el desarrollo sostenible.

3. Propender por el mejoramiento de la calidad de vida de los habitantes, la distribución equitativa de las oportunidades y los beneficios del desarrollo y la 
preservación del patrimonio cultural y natural.

4. Mejorar la seguridad de los asentamientos humanos ante los riesgos naturales'.

A pesar de ello, es cuestionable la voluntad de las fuerzas privadas y estatales para promover patrones de desarrollo sostenible y cobran gran relevancia los análisis sobre la urbanización latinoamericana anteriormente planteados.

\section{Hacia una nueva visión de la ciudad}

Debe tenerse en cuenta que a nivel mundial, la profundidad y escala de la pobreza en zonas rurales es más alta, aunque a veces menos visible que en la ciudad. Los responsables de la mayor degradación ambiental ocasionada por las ciudades (en recursos naturales, desechos, contaminación, gases de efecto invernadero), son determinadas industrias y empresas, así como grupos de ingreso medio y alto que son grandes consumidores, los cuales muchas veces viven en suburbios de baja densidad.

Las ciudades, al concentrar la producción y la población, permiten sostener condiciones de vida segura, saludable, culturalmente rica y con niveles relativamente bajos en el consumo de energía, en el uso de recursos y en la producción de desechos, obteniendo ventajas sobre los asentamientos dispersos. De esta forma, disminuyen los costos para el suministro de agua tratada y entubada, el tra- tamiento de desechos, las telecomunicaciones, la salud, la educación, la provisión de servicios de emergencia. La concentración de la producción y el consumo, incrementan la posibilidad para un uso eficiente de los recursos, mediante la recuperación y reciclaje de materiales. La mayor concentración de la población en la ciudad, reduce la demanda de la población por la tierra. En la ciudad se han desarrollado en mayor grado la 'economía social', con la cual se abarca gran variedad de iniciativas y acciones organizadas, controladas localmente y sin ánimo de lucro (Centro de las Naciones Unidas para los Asentamientos Humanos, 1996).

Para el logro de las ventajas mencionadas, debe desarrollarse una estructura económico-social e institucional que permita administrar el desarrollo urbano, ya que la buena gobernabilidad puede generar mayor ganancia económica y social, así como menor degradación ambiental. De esta forma puede definirse como exitosa a una ciudad cuando satisface objetivos de sus habitantes y empresas, sin transmitir los costos a otra gente (incluidas las generaciones futuras) o a su región.

Como criterios importantes a ser tenidos en cuenta para evaluar si una ciudad está comprometida con el desarrollo sostenible, se mencionan:

- Calidad de vida, incluyendo los niveles de pobreza, exclusión social, integración y estabilidad socio-política.

168 Ramón Alberto Serna I. 
- Escala de uso de recursos no renovables e incidencia del reciclaje en la misma.

- Escala y naturaleza del uso de recursos naturales renovables, grado de aseguramiento para niveles de demanda sostenibles y consideración de la huella ecológica del asentamiento.

- Escala y naturaleza de desechos no reusables y su impacto sobre la salud humana, los sistemas naturales y los servicios.

La Resolución 15/11, adoptada por la Comisión de las Naciones Unidas sobre Asentamientos Humanos (1995 citado por Centro de las Naciones Unidas para los Asentamientos Humanos, 1996), plantea como criterios importantes para implementar el desarrollo sostenible al interior de las ciudades:

a) Buscar no sólo proteger el medio ambiente, sino un nuevo concepto de desarrollo económico, sin destruir los recursos naturales y la capacidad de sustento del planeta.

b) Los pilares del desarrollo sostenible son la sostenibilidad ambiental, económica y social.

c) La concentración humana en la ciudad constituye un componente esencial en la producción insostenible y en el consumo.

d) Durante el desarrollo urbano se deben tomar acciones vigorosas para evitar el deterioro de los recursos de tierra, agua y atmósfera.

e) El crecimiento demográfico y la urbanización tienen implicaciones adversas para el suministro de vivienda adecuada, infraestructura y servicios ambientales.

f) Las ciudades contribuyen desproporcionadamente a la productividad nacional y son importantes para el avance cultural y el desarrollo social.

g) El rápido crecimiento urbano, ocasiona incorporación de asentamientos rurales, en ocasiones con deterioro del medio ambiente.

h) Los pobres, con frecuencia no pueden pagar tierra urbana idónea y residen en áreas con infraestructura inadecuada.

i) Los desastres naturales requieren intervenciones externas, además de respuestas individuales y comunales.

j) Las causas reales de la vulnerabilidad a los riesgos naturales son los problemas ambientales y de equidad, por lo cual, concomitante con la intervención externa, debe continuarse apoyando el desarrollo económico general.

Para abordar esta problemática se plantea la implementación de medidas que promuevan el desarrollo sostenible de los asentamientos humanos como descentralizar la toma de decisiones, crear un ambiente facilitador para apoyar iniciativas de las autoridades locales y de las organizaciones comunitarias; establecer 
estructuras regulatorias y de incentivos que promuevan el uso sostenible de recursos; uso de tecnologías no contaminantes en los asentamientos humanos; incrementar recursos financieros para promover objetivos de desarrollo urbano sostenible; facilitar el acceso a la tierra y seguridad de tenencia para los habitantes urbanos, acompañado de un mejoramiento de la planeación y gestión del uso del suelo; reforzar las medidas de conservación que minimicen la degradación física y la contaminación ambiental; reforzar el papel de la tierra como centro de finanzas municipales; compilar inventarios nacionales de tierra y otros recursos ecológicos y formular estrategias para guiar el desarrollo de los recursos de tierra.

Dentro de este contexto, el ordenamiento territorial, como proceso técnico-político que busca actuar sobre el orden territorial existente para inducir nuevos escenarios de desarrollo, uso y ocupación coherentes con una nueva imagen objetiva previamente concertada por la sociedad (Massiris Cabeza, 1999), constituye una poderosa visión que puede ayudar a orientar el desarrollo hacia la sostenibilidad.

\section{Conclusiones}

El trato conceptual homogeneizante del desarrollo sostenible por parte de las diferentes escuelas de pensamiento, que consideran comunes los conceptos de ambiente, futuro e igualdad, ha hecho disminuir la fuerza que había alcanzado a principios de la década de los noventa.
Así mismo, la ambigüedad que surge al considerar el desarrollo sostenible como un valor que incorpora ideales personales, aspiraciones, conceptos y que fijan en general objetivos sociales, crean laxitud en aspectos prácticos y hacen difícil su operacionalidad. Esta misma naturaleza subjetiva, en la cual es relevante la valoración del medio ambiente por la sociedad, hace necesaria su contextualización para que sea funcionalmente operativa y la somete al riesgo de la manipulación política, pero al mismo tiempo ha permitido abrir la polémica en torno al desarrollo económico.

Los sistemas de desarrollo sostenible son en general sensitivos a las restricciones ecológicas y por lo tanto a la información sistémica y tienen en cuenta las variables ambientales, así como el rescate cultural y las formas de participación ciudadana. Es por ello conveniente implementar un mejor ajuste a las condiciones medioambientales en la ciudad, lo cual no significa una visión determinista de las relaciones entre la ciudad y el medio ambiente, sino que se debe promover que el valor de los bienes y servicios refleje el costo de producción, permeando la equidad todo el proceso productivo. Por otra parte, la lógica económica y los acuerdos prevalecientes han sido poco coherentes con estas restricciones.

Para hacer viables las premisas del desarrollo sostenible, fundamentadas en que el manejo adecuado del medio depende de una sociedad justa e igualitaria, es necesario modificar las estructuras institucionales y políticas de tal forma que se

170 Ramón Alberto Serna I. 
promuevan procesos de participación ciudadana y se propicie una mejor gobernabilidad. De la misma manera, deben ocurrir cambios en los sistemas económicos para que estos permitan generar excedentes a través de tecnologías innovadoras, adaptadas a las condiciones sistémicas locales, es decir, deben ser seguras y sostenibles; los sistemas sociales deben garantizar la equidad; es necesario que los sistemas administrativos sean flexibles y capaces de autocorrección; así como sistemas internacionales que promuevan patrones sostenidos de comercio y financiación.

Hacia el futuro, las características del medio ambiente como sumidero serán relevantes y en este sentido se deben orientar iniciativas como el reciclamiento, la racionalidad energética y productiva, así como el rediseño de productos y tecnologías, entre otras.

El desarrollo sostenible puede ser abordado desde diversas perspectivas dependiendo de los objetivos que se persigan, pero en general pueden enmarcarse dentro de tres visiones generales, económica, ecológica y sociológica.

Debe ampliarse la perspectiva de futuro de los planes de Desarrollo y de los Planes de Ordenamiento Territorial, lo que implica promover sistemas de desarrollo que rompan con la dependencia en el corto plazo.

El ordenamiento territorial constituye un poderoso instrumento para el logro de los objetivos de desarrollo sostenible en las ciudades, ya que puede incidir en evitar externalidades indeseadas, mediante el óptimo uso del suelo y la promoción de procesos que promuevan un desarrollo más equitativo. Los Planes de Ordenamiento Territorial deben involucrar propuestas tendientes a disminuir la huella ecológica de las ciudades, como el estímulo a la producción de biomasa; la reducción en la producción de desechos y su reciclamiento; deben promover la eficiencia en el uso de recursos importados, al igual que desarrollos urbanos relativamente densos y redes de transporte público eficientes. Estas iniciativas deben estar permeadas con propuestas que generen una mayor democratización en la ciudad, así como mayor participación ciudadana, gobernabilidad y estabilidad socio-política, seguridad ciudadana, fortalecimiento de la administración comunitaria o estatal, entre muchos otros aspectos que conduzcan a una sostenibilidad ambiental, económica y social.

La apertura de las ciudades en los procesos de globalización, hace de estos sistemas cada vez más abiertos, más dependientes de factores externos y probablemente conducirá a una menor capacidad para controlar y mantener su funcionamiento dentro de límites homeostáticos que permitan garantizar la sostenibilidad del sistema.

Las estrategias neoliberales que consideran que es posible extender el desarrollo sin deteriorar las condiciones ambientales, continúan estimulando el consumo y los procesos acumulativos como valores culturales. Frente a ello, debe promoverse 
un cambio cultural basado en la solidaridad y en la ética particular y compartida.

Desde las perspectivas empresariales, debe estimularse la adopción de tecnologías y sistemas de producción que permitan una productividad enmarcada en conceptos de sostenibilidad, así como el uso de nuevos indicadores y métodos de evaluación que permitan un seguimiento integral del comportamiento económico.

Deben rescatarse los saberes múltiples como factores que conduzcan a un desarrollo sostenible, lo que implica revaluar la hegemónica exclusividad del conocimiento técnico-científico como el único válido y promover y rescatar los valores adaptativos de la cultura y la capacidad de aprendizaje e inventiva individual y colectiva que permitan cambiar patrones consumistas de desarrollo por otros más razonados, valorativos y éticos. Se plantea la necesidad de pensar los problemas ambientales como sistemas complejos que reflejan comportamientos sinérgicos/antagónicos y que por lo tanto implican cambiar el tradicional enfoque centrado en variables oligodimensionales.

Sería conveniente estudiar, bajo perspectivas enmarcadas en la Teoría General de Sistemas y los Sistemas Complejos, el efecto entrópico de la acumulación histórica de capital (fijo y variable) que podrían generar las ciudades, así como los umbrales e irreversibilidades y la saturación en los sistemas urbanos. Deben iniciarse investigaciones en torno a la huella ecológica de las ciudades y las relaciones entre intercambios, externalidades, normativa y el 'dumping' ambiental.

172 Ramón Alberto Serna I. 


\section{Bibliografía}

Cardoso, Fernando Henrique. Knowledge and political practice. En: Fals Borda, Orlando, comp.: People's participation: Challenges ahead. Bogotá: Colciencias, 1998. pp. 11-18.

Carrión, Diego. La reforma urbana en un contexto de sustentabilidad. En: El desarrollo sustentable y las Metrópolis Latinoamericanas. (1996: México). Segundo Foro del Ajusco. México: El Colegio de México, 1996. pp. 125-129.

Carrizosa, Julio. La sostenibilidad de la ciudad. En: La ciudad: hábitat de diversidad y complejidad. Santafé de Bogotá: Universidad Nacional de Colombia, 2000. pp. 278-287.

Carrizosa, Julio. La evolución del debate sobre el desarrollo sostenible. En: La gallina de los huevos de oro: Debate sobre el concepto de desarrollo sostenible. Bogotá: ECOFONDO-CEREC, 1998. pp. 44-68.

.Evolución del concepto de desarrollo sostenible. En: Gestión y Ambiente. (2000: Medellín). Memorias Primer Seminario Desarrollo Sostenible Energía y Paz. Medellín: Universidad Nacional de Colombia. 2000. pp. 9-18.

Centro de las Naciones Unidas para los Asentamientos Humanos (Hábitat). Un mundo en proceso de urbanización: Informe Mundial sobre los Asentamientos Humanos 1996. Tercer Mundo: Bogotá, 1996. 2 Tomos.

Cepaur. 1986. Desarrollo a escala humana: una opción para el futuro. Fundación Dag Hammarskjöld, s.l. pp. 1-19.

Colombia. Congreso de la República. Ley 99 de 1993, por la cual se crea el Ministerio del Medio Ambiente, se reordena el sector público encargado de la gestión y conservación del medio ambiente y los recursos naturales renovables, se organiza el Sistema Nacional Ambiental (Sina), y se dictan otras disposiciones. Bogotá: El Congreso, 1993.

Colombia. Congreso de la República. Ley 388 del 18 de julio de 1997: 'Por la cual se modifica la Ley 9a. de 1989 y la Ley 3a. de 1991 y se dictan otras disposiciones'. Bogotá: El Congreso, 1997. $29 \mathrm{p}$.

Colombia. Contraloría General de la República. Fundamentos metodológicos para la valoración de los costos ambientales. Santafé de Bogotá: La Contraloría, 1994. 60 p. (Documento OP - No. 004). 
Colombia. Corporación Autónoma Regional de Cundinamarca. Resolución CAR No. 1080 de 1998: Determinantes Ambientales para los Planes de Ordenamiento Territorial Municipal. Bogotá: La Corporación, 1998. 23 p.

Colombia. Departamento Administrativo de Planeación/Alcaldía Mayor de Bogotá, D. C. Las Unidades de Planeamiento Zonal (UPZ). Bogotá: Subdirección de Expansión y Ordenamiento Regional, Alcaldía Mayor de Bogotá, D. C. 7 p. (Documento ejecutivo).

Colombia. Departamento Nacional de Planeación. El proceso de descentralización en el Plan de Desarrollo Cambio para Construir la Paz, 1998-2002. En: Hacia un Estado Participativo. Bogotá: la entidad, 1998. pp. 111-130.

Dovers, Stephen. Sustainability: Definitions, Clarifications and Contexts. En: Journal of SID. Vol. 2, No. 3 (1989); pp. 33-36.

Fals Borda, Orlando, comp. People's participation: Challengues ahead. Bogotá. Colciencias, $1998.253 \mathrm{p}$.

Flórez, Antonio y Thomas, Javier. La teoría general de sistemas. En: Cuadernos de Geografía: Revista del Departamento de Geografía, Facultad de Ciencias Humanas, Universidad Nacional de Colombia. Vol. 4, No. 1/2 (1993); pp. 111-137.

FUNDAGRO. La sostenibilidad en el sector agropecuario. En: Cuadernos de Desarrollo Agrícola. Vol., No. 2/3 (1996); pp. 109-156.

García, Rolando. Interdisciplinariedad y sistemas complejos. En: Leff, Enrique (comp.). Ciencias Sociales y Formación Ambiental. Barcelona: Gedisa, 1994. pp. 85-124.

Iriarte, Alfredo. Breve historia de Bogotá. Bogotá. Oveja Negra, 1988. 263 p.

Jaramillo, Samuel. El desenvolvimiento de la discusión sobre la urbanización Latinoamericana: ¿Hacia un nuevo paradigma de interpretación? s.p.i., s.f.

Lacy, Rodolfo. Desarrollo sustentable y metabolismo urbano. En: El desarrollo sustentable y las metrópolis latinoamericanas. (1996: México). Segundo Foro del Ajusco. México: El Colegio de México, 1996. pp. 119-124.

Leff, Enrique. Sociología y ambiente: Formación socioeconómica, racionalidad ambiental y transformaciones del conocimiento. En: Leff, Enrique (comp.). Ciencias Sociales y Formación Ambiental. Barcelona: Gedisa, 1994. pp. 17-84.

Lewis, Arthur W. Economic Growth Theory. London: Allen \& Unwin, 1955. 435 p.

Massiris Cabeza, Ángel. Ordenamiento Territorial: experiencias internacionales y desarrollos conceptuales y legales realizados en Colombia. En: Perspectiva Geográfica: Revista del Programa de Estudios de Posgrado en Geografía de la Universidad Pedagógica y Tecnológica de Colombia. No. 4 (1999); pp. 7-75.

Max-Neef, Manfred. Economy, humanism and neoliberalism. En: Fals Borda, Orlando, comp. : People's participation: Challenges ahead. Bogotá: Colciencias, 1998. pp. 63-79.

174 Ramón Alberto Serna I. 
Méndez, Ricardo. Geografía económica: La lógica espacial del capitalismo global. Barcelona. Ariel, $1997.384 \mathrm{p}$.

Mertins, Günter. La suburbanización poblacional de Santa Fé de Bogotá: hacia la Sabana de Bogotá. En: Perspectiva Geográfica : Revista del Programa de Estudios de Posgrado en Geografía de la Universidad Pedagógica y Tecnológica de Colombia. No. 4 (1999); pp. 99-116.

Restrepo, Juan Camilo. Reflexiones sobre El Salto Social. En: Economía Colombiana. S.n. (1995); pp. 6-12.

Robirosa, Mario. El desarrollo sustentable y las metrópolis latinoamericanas. En: El desarrollo sustentable y las metrópolis latinoamericanas. (1996: México). Segundo Foro del Ajusco. México: El Colegio de México, 1996.

Sarmiento Palacio, Eduardo. Financiamiento y limitaciones institucionales del Salto Social. En: Economía Colombiana. S.n. (1995); pp. 14-25.

Sunkel, Osvaldo y Paz, Pedro. Los conceptos de desarrollo y subdesarrollo. En: El subdesarrollo latinoamericano y la teoría del desarrollo. 23 ed. México : Siglo XXI, 1991. p. 13-40

Torres Toro, Ricardo. Desarrollo tecnológico para una agricultura sostenible en Colombia. En: Ramírez, Jorge et al., eds. Foro Nacional Ambiental Agro y Medio Ambiente. Bogotá: FESCOL, 1998. pp. 131-150.

Tudela, Fernando. Hacia una cultura de sustentabilidad urbana. En: El desarrollo sustentable y las Metrópolis Latinoamericanas. (1996: México). Segundo Foro del Ajusco. México: El Colegio de México, 1996. pp. 145-153.

Universidad Javeriana. Taller sobre desarrollo sustentable. S.l. s.f. 44 p.

Unwin, Tim. El lugar de la geografía. Madrid: Cátedra, 1995. 341 p.

Vazco, Mauricio y Pérez Preciado, Alfonso. Concertación del POT de Bogotá. Conferencia dictada el 4 de mayo de 2001. Bogotá: Instituto Geográfico Agustín Codazzi.

World Commission on Environment and Development. Our common future. Oxford: Oxford University Press, 1987.383 p.

Vallejo Zamudio, Luis E. La Planeación en Colombia y el Plan de la Revolución Pacífica: Una Aproximación Teórica. En: Plan de Desarrollo: un Modelo para Armar. Tunja: Universidad Pedagógica y Tecnológica de Colombia, s.f. pp. 28-30. 
176 Ramón Alberto Serna I. 